\title{
Influence of unstable psychological condition on the quality of life of hemodialysis patients
}

\author{
Junko Takahashi ${ }^{1}$, Takaya Abe ${ }^{1 *}$, Mariko Kaneko², Nariyuki Sasaki ${ }^{3}$, Yumiko Takasawa ${ }^{3}$, Tetsuo Kato ${ }^{3}$, \\ Tomohiko Matsuura', Jun Sugimura', Kentaro Fukumoto ${ }^{4}$, Kotaro Otsuka ${ }^{4}$ and Wataru Obara ${ }^{1}$
}

\begin{abstract}
Purpose: Hemodialysis patients tend to be in "unstable psychological conditions" because of complications and physical activity restriction. This study aimed to investigate unusual psychological factors and their influence on the quality of life $(\mathrm{QOL})$ of hemodialysis patients.

Methods: This study targeted 55 patients who had experienced $>1$ year of stable maintenance outpatient hemodialysis. The Hospital Anxiety and Depression Scale (HADS) was used to evaluate unusual psychological conditions. The Kidney Disease Quality of Life Short Form (KDQOL-SF) was used to evaluate QOL. Participants were grouped into "unstable psychological conditions" if HADS indicated that "depression is suspected" or "suspected depression, anxiety stated" ("Anxiety/Depression group"); this group was then compared to the "Stable group".

Results: A total of 18 participants (32.7\%) were included in the "Anxiety/Depression group", and all QOL scores in this group were lower than those in the "Stable group". In particular, a significantly low value was shown in the respective criteria such as "effects of kidney disease," "social support," and "general health perceptions".

Conclusions: A possibility was suggested that the major causes were the restrictions of social activity by hospital visits and treatment and unique psychological conditions.
\end{abstract}

Keywords: Hemodialysis patents, Psychological conditions, Quality of life (QOL), Hospital Anxiety and Depression Scale (HADS), Kidney Disease Quality of Life Short Form (KDQOL-SF)

\section{Introduction}

The estimated 5-year survival rate of chronic dialysis patients in Japan is $60 \%$. Despite advances in medicine for the past 30 years, this rate remains the same [1]. Dialysis patients have not only chronic diseases with poor prognosis but also physical limitations due to various complications, as well as restrictions of social activity by hospital visits and treatment. For these reasons, dialysis patients encounter various loss experiences and psychological conditions leading to "reactive

\footnotetext{
* Correspondence: takayabe@iwate-med.ac.jp

'Department of Urology, School of Medicine, Iwate Medical University, 2-1-1, Idaidori, Yahaba-cho, Shiwa-gun, Iwate 028-3695, Japan

Full list of author information is available at the end of the article
}

depressed state." Approximately 5-71.4\% of dialysis patients are reported to suffer from depressive state [2], and this rate varies widely. This is considered to be due to the difficulty in obtaining an objective diagnosis. Previous studies reported that depression increased the risk of mortality [3-6]. However, only a few studies have evaluated the influence of "unusual psychological conditions" on the quality of life (QOL) of dialysis patients.

"A decline in QOL" due to illness causes "unstable psychological conditions." On the contrary, "unstable psychological conditions" caused by illness may "decrease QOL," and "unstable psychological conditions" and "decline in QOL" are mutually vicious cycles. Given

(c) The Author(s). 2020 Open Access This article is licensed under a Creative Commons Attribution 4.0 International License, which permits use, sharing, adaptation, distribution and reproduction in any medium or format, as long as you give appropriate credit to the original author(s) and the source, provide a link to the Creative Commons licence, and indicate if changes were made. The images or other third party material in this article are included in the article's Creative Commons licence, unless indicated otherwise in a credit line to the material. If material is not included in the article's Creative Commons licence and your intended use is not permitted by statutory regulation or exceeds the permitted use, you will need to obtain permission directly from the copyright holder. To view a copy of this licence, visit http://creativecommons.org/licenses/by/4.0/ The Creative Commons Public Domain Dedication waiver (http://creativecommons.org/publicdomain/zero/1.0/) applies to the data made available in this article, unless otherwise stated in a credit line to the data. 
the varying findings, this study aimed to evaluate the effect of "unstable psychological conditions" such as depression and anxiety on the QOL of hemodialysis patients and to examine possible interventions for this population.

\section{Subjects and methods}

This study included patients undergoing maintenance hemodialysis at Seitetu Memorial Hospital. The inclusion criteria were as follows: (1) dialysis duration of $\geq 1$ year, (2) no history of hospitalization for $\geq 1$ year, (3) not living alone, and 4) provided consent for participation in this study. A total of 55 hemodialysis patients met the above criteria and thus were included in the study. The study was approved by the Seitetu Memorial Hospital Ethics Committee (approval number: 011). All patients provided a written informed consent.

The Hospital Anxiety and Depression Scale (HADS) [7] was used for the evaluation of "unstable psychological conditions." For the evaluation of QOL, the Kidney Disease Quality of Life Short Form (KDQOL-SF version 1.3) [8] was used.

HADS was developed to evaluate anxiety and depressed state of patients with physical symptoms. HADS consists of a total of 14 items (seven items on anxiety (A item) and seven items on depression (D item)) (Table 1), and $\mathrm{A}$ and D items are alternately arranged. Each item is assigned 0 to 3 points, which obtains a total score of 21 points: the highest score indicates the poorest state. The reliability and validity of the Japanese version of HADS have been reported [9]. The patients with "unstable psychological conditions" were defined as those who scored

Table 1 Hospital Anxiety and Depression Scale

A item
Q1. I feel tense or wound up:
Q3. I get a sort of frightened feeling as if something awful is about to
happen:
Q5. Worrying thoughts go through my mind:
Q7. I can sit at ease and feel relaxed:
Q9. I get a sort of frightened feeling like "butterflies" in the stomach:
Q11. I feel restless as if I have to be on the move:
Q13. I get sudden feelings of panic:
Ditem
Q2. I still enjoy the things I used to enjoy:
Q4. I can laugh and see funny side of things:
Q6. I feel cheerful:
Q8. I feel as if I am slowed down:
Q10. I have lost interest in my appearance:
Q12. I look forward with enjoyment to things
Q14. I can enjoy a good book or radio or TV program:

eight points or above in HAD-D items which were to identify those suspected of depression or those who did eight points or above in HADS-A items which were to identify those suspected of anxiety [7, 10]. In order to examine the inspection results and the QOL on "unstable psychological conditions," patients who satisfied these conditions were grouped as the "Anxiety/Depression group" and the other patients as the "Stable group."

KDQOL-SF was developed by Hays et al. [11], and the reliability and validity of the Japanese version of KDQOL-SF has been reported [12]. KDQOL consists of 11 items on the kidney-disease-targeted scale and eight items on the general health-related QOL scale. The kidney-disease-targeted scale questionnaire consisted of items on symptoms, physical problems, effects of kidney disease, burden of kidney disease, work status, cognitive function, quality of social interaction, sexual function, sleep, social support, dialysis staff encouragement, and patient satisfaction with dialysis care. Moreover, the general health-related QOL scale questionnaire consisted of items on physical functioning, role functioning (physical), body pain, general health perceptions, vitality, social functioning, role functioning (emotional), and mental health. The higher the score, the better the QOL. For this study, we obtained approval to use the Japanese version of KDQOL-SF version 1.3 from author.

In addition, for the examinations of the patients' backgrounds, the average annual values obtained from their periodical blood tests were used.

For statistical analysis, $\chi 2$ test, Mann-Whitney's $U$ test, and Pearson's correlation coefficient test were performed. JMP (JMP 13.2 for Windows, SAS Institute Inc., USA) was used for analysis, with a significance level of less than $5 \%$. Continuous variables are expressed as mean \pm standard deviation; categorical variables are expressed as count.

\section{Results}

The mean age of the subjects was $67.3 \pm 12.0$ years; the mean dialysis duration was $10.0 \pm 7.9$ years; and 19 patients (34.5\%) had diabetes as primary disease (Table 2). Eighteen subjects were diagnosed as having "unstable

Table 2 General characteristics of subjects

\begin{tabular}{ll}
\hline Male/female $(n)$ & $39 / 16$ \\
\hline Age (years) & $67.3 \pm 12.0$ \\
Vintage of dialysis (years) & $10.0 \pm 7.9$ \\
Dialysis time (min) & $244.4 \pm 21.9$ \\
Diabetes/non-diabetes & $19 / 36$ \\
HADS score & \\
$\quad$ A item & $2.5 \pm 2.9$ \\
D item & $5.8 \pm 3.2$ \\
\hline
\end{tabular}


psychological conditions" based on HADS, which was $32.7 \%$ of the total (Fig. 1). Moreover, no significant difference was found between the "Anxiety/Depressed group" and the "Stable group" in terms of patient background (Table 3). In the test results, "Anxiety/Depression group" demonstrated a value significantly lower than that for "Stable group" in Hb level and normal Protein Catabolic Rate (nPCR) respectively (Table 4). The results of KDQOL-SF between the two groups are shown in Tables 5 and 6. The "Anxiety/Depression group" shows low values in all items compared to the "Stable group". In particular, "effects of kidney disease," "cognitive function," "social support," "general health perceptions," and "mental health" items show significant low values. There were many missing values for the "sexual function" item; thus, the calculation of its average value was considered inaccurate, and it was subsequently excluded from the analysis.

\section{Discussion}

Many dialysis patients suffer from treatment-related stressors such as diet and fluid limitations, temporary restraints during dialysis therapy, itching and general fatigue, and financial problems [13, 14]. Therefore, dialysis patients are more likely to develop depression than healthy people. HADS used in this study does not deal with the items depending on a disease including such as insomnia and anorexia and has been proved to have certain usability as a method to understand the mental states of the patients with a disease [7, 15]. In addition, the effectiveness of Japanese-version HADS has been reported [9]. It is assumed that those patients who scored
Table 3 General characteristics of the Anxiety/Depressed group and Stable group

\begin{tabular}{lll}
\hline & Stable group & Anxiety/depression group \\
& $n=37$ & $n=18$ \\
\hline Male/female $(n)$ & $27 / 10$ & $12 / 6$ \\
Age (years) & $67.6 \pm 11.2$ & $66.7 \pm 14.0$ \\
Vintage of dialysis (years) & $10.5 \pm 8.5$ & $8.9 \pm 6.7$ \\
Diabetes/non-diabetes ( $n$ ) & $12 / 25$ & $7 / 11$ \\
Dialysis time (min) & $242.4 \pm 20.5$ & $248.3 \pm 24.8$ \\
\hline
\end{tabular}

eight points or more in HADS-A (sensitivity: 0.89/ specificity: 0.88 ) and those scoring eight points or more in HADS-D (sensitivity: $0.80 /$ specificity: 0.75) are suspected of suffering from anxiety and depression, respectively [10]. Accordingly, in this study, those patients presenting eight points or more in any one of these tests were defined as the group of patients who took on "unstable psychological conditions" ("Anxiety/Depression group").

In a meta-analysis, Palmer et al. revealed that the prevalence of interview-based depression in chronic kidney disease stage 5D was $22.8 \%$ and that using self- or clinician-administered rating scales was $39.3 \%$ [16]. In an international collaborative research using the Center for Epidemiological Studies Depression Scale (CES-D) score, which included 5872 patients and 1603 dialysis patients in Japan, depressive symptoms become stronger or depression symptoms appear more frequently in patients with CES-D score of $\geq 10$ points at an estimated prevalence rate of $40.0 \%$, which is almost equal to those reported in foreign countries [17].

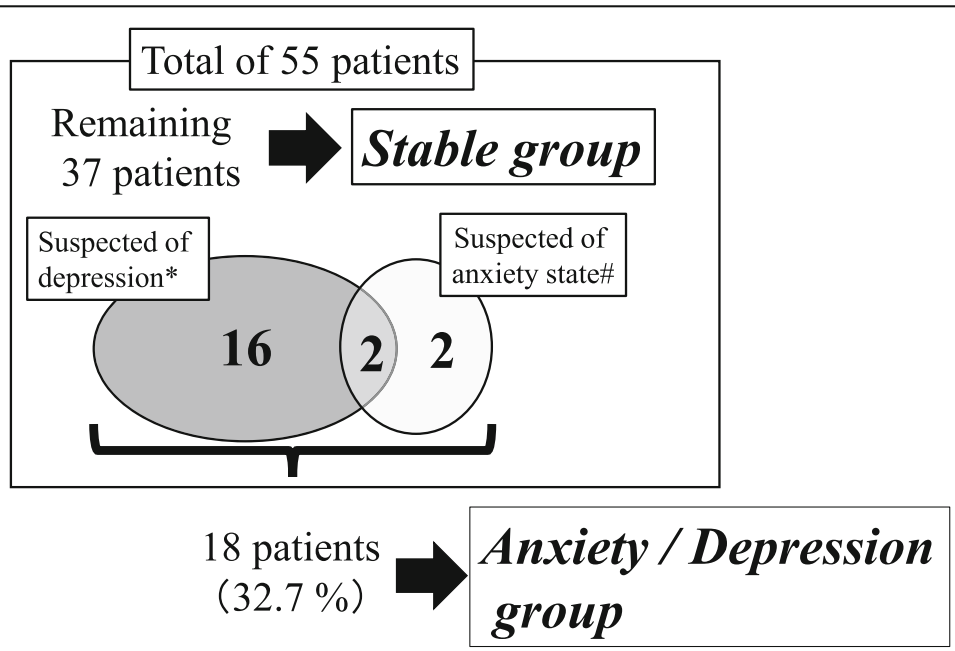

*The D item of HADS is 8 points or more \#The A item of HADS is 8 points or more

Fig. 1 Definition of the "Anxiety/Depression group" and "Stable group." "Unstable psychological condition" is defined as a score of $\geq 8$ points on the $D$ items of HADS, which indicates suspected of depression, and/or a score of $\geq 8$ points on the A items of HADS, which indicates suspected of anexiety 
Table 4 Blood test of the Anxiety/Depressed group and Stable group

\begin{tabular}{llll}
\hline & Stable group & Anxiety/depression group & $p$ value \\
\hline Albumin $(\mathrm{g} / \mathrm{dL})$ & $3.47 \pm 0.34$ & $3.35 \pm 0.61$ & 0.597 \\
adjusted calcium (mg/dL) & $8.94 \pm 0.30$ & $8.73 \pm 1.49$ & 0.360 \\
Phosphorus(mg/dL) & $5.83 \pm 1.04$ & $5.53 \pm 1.08$ & 0.441 \\
Creatinine $(\mathrm{mg} / \mathrm{dL})$ & $10.52 \pm 1.91$ & $10.49 \pm 2.77$ & 0.409 \\
Hemoglobin(g/dL) & $11.71 \pm 2.35$ & $10.56 \pm 1.55$ & 0.015 \\
$\mathrm{Kt} / \mathrm{n}$ & $1.55 \pm 0.24$ & $1.50 \pm 0.32$ & 0.823 \\
$\mathrm{nPCR}(\mathrm{g} / \mathrm{kg} /$ day) & $0.89 \pm 0.11$ & $0.83 \pm 0.18$ & 0.029 \\
$\% C G R(\%)$ & $102.12 \pm 18.14$ & $100.79 \pm 26.77$ & 0.146 \\
\hline
\end{tabular}

The number of patients who were suspected of suffering from "depression" in this research (scoring eight points or more in HADS-D) was relatively small, 16 patients (29.1\%), which was assumed to be attributable to the fact including that different diagnostic criteria were used.

Depression in hemodialysis patients has been reported to increase the risk of mortality [3-6]. In the Dialysis Outcomes and Practice Patterns Study (DOPPS), depression is considered to be a risk factor of death and hospitalization; DOPPS is an international observational study on the contents of medical treatment of chronic hemodialysis patients and their treatment results $[4,17]$ The same result was found among hemodialysis patients in Japan [17]. In contrast, a lower health-related QOL using KDQOL-SF was associated with a higher risk of death and hospitalization [18].

"Anxiety/Depression group" showed a low value in respective tests of KDQOL-SF in this research as well, and therefore, it was thought that attentions should be paid from both mentally and QOL. Also, comparing to "Stable group," "Anxiety/Depression group" demonstrated a significantly lower score in $\mathrm{Hb}$ level and nPCR. A multivariate logistic regression analysis was performed for blood test (Table 7). The risk of developing "unstable psychological conditions" was significantly lowered as increased of $\mathrm{Hb}$ and PCR (adjusted odds ratio 0.150 and 5.244e-7, 95\% confidence interval $0.034-0.656$ and $1.59 \mathrm{e}-7-0.017$, respectively).

Anemia has been reported to be related to depression [19-21]. There is a possibility that anemia can cause or worsen depression because dyspnea or general fatigue caused by anemia can decrease physical and social activity. In dialysis patients, easygoing interventions for treating anemia is dangerous. In dialysis patients, an increase in $\mathrm{Hb}$ may increase the risk of embolism. Therefore, it is considered necessary to examine target $\mathrm{Hb}$ in dialysis patients in the future from a mental point of view as well.

There has been some reports on the correlation between the indexes for nutritional statuses and mental states [22, 23]. It was considered to be significant to take enough protein while paying attention to the serum phosphorus level.

"Anxiety/Depression group" demonstrated low KDQOL scores in general and also showed significantly low ones especially in the respective criteria such as "effects of kidney disease," "cognitive function," "social support," "general health perceptions," and "mental health" (Tables 5 and 6). Looking at the questions of "Effects of kidney disease on your daily life," significantly low values were obtained with regard to the question of "Your

Table 5 Scores on Kidney Disease Quality of Life Short Form (kidney-disease-targeted scale)

\begin{tabular}{llll}
\hline & Stable group & Anxiety/depression group & $p$ value \\
\hline Symptoms and problems & $88.06 \pm 10.45$ & $84.24 \pm 18.65$ & 0.2922 \\
Effects of kidney disease & $88.22 \pm 12.45$ & $80.94 \pm 18.55$ & 0.0384 \\
Burden of kidney disease & $50.51 \pm 27.77$ & $48.31 \pm 32.83$ & 0.1443 \\
Work status & $22.97 \pm 25.26$ & $22.81 \pm 27.37$ & 0.4846 \\
Cognitive function & $95.68 \pm 10.09$ & $90.45 \pm 18.52$ & 0.0358 \\
Quality of social interaction & $96.40 \pm 6.21$ & $88.83 \pm 21.99$ & 0.1350 \\
Sleep & $81.76 \pm 18.09$ & $78.71 \pm 19.93$ & 0.0841 \\
Social support & $86.91 \pm 16.76$ & $81.51 \pm 22.81$ & 0.0183 \\
Dialysis staff encouragement & $77.03 \pm 15.45$ & $72.29 \pm 18.94$ & 0.3931 \\
Patient satisfaction with dialysis care & $86.48 \pm 11.68$ & $80.90 \pm 19.13$ & 0.1956 \\
\hline
\end{tabular}


Table 6 Scores on Kidney Disease Quality of Life Short Form (general health-related quality of life scale)

\begin{tabular}{llll}
\hline & Stable group & Anxiety/depression group & $p$ value \\
\hline Physical functioning & $72.97 \pm 25.40$ & $72.24 \pm 23.78$ & 0.5337 \\
Role functioning (physical) & $67.57 \pm 44.82$ & $62.50 \pm 43.04$ & 0.3050 \\
Body pain & $79.93 \pm 29.13$ & $77.40 \pm 27.58$ & 0.2557 \\
General health perceptions & $50.27 \pm 20.14$ & $45.01 \pm 23.76$ & 0.0230 \\
Vitality & $67.70 \pm 25.13$ & $59.08 \pm 26.69$ & 0.0579 \\
Social functioning & $88.85 \pm 23.90$ & $88.58 \pm 21.18$ & 0.4493 \\
Role functioning (emotional) & $90.09 \pm 29.26$ & $80.55 \pm 36.46$ & 0.0597 \\
Mental health & $85.95 \pm 12.60$ & $76.53 \pm 22.22$ & 0.0023 \\
\hline
\end{tabular}

ability to travel?" and "Stress or worries caused by kidney disease?" Collectively, a possibility was suggested that the major causes were the restrictions of social activity by hospital visits and treatment and unique psychological conditions. The important measures were considered to be the removal of patients' anxiety through the continuous provision of detailed information on their individual clinical conditions by medical staff including doctors and the medical staffs from their surroundings including family members. In addition, personal psychotherapy on the bedside during dialysis therapy was found to improve depression symptoms, QOL, and fluid adherence [24]. The involvement of medical staff is also important. The improvement in these particularities and the support of dialysis patients are deemed to become significant from now on.

Incidentally, compared with the "Stable group," the "Anxiety/Depression group" also showed significantly lower "cognitive function" items. Therefore, "cognitive function" may affect the HADS result. We will need to pay due attention to the influence of cognitive function in the future, considering the ever-increasing number of elderly dialysis patients.

CVD and other complications could affect the HADS scale. However, HADS was developed to evaluate anxiety and depressed state of patients with physical symptoms. And no significant difference between the two groups

Table 7 Multivariate logistic regression analysis for risk factor to develop "unstable psychological conditions"

\begin{tabular}{lll}
\hline Variable & Odds ratio $(95 \% \mathrm{Cl})$ & $p$ value \\
\hline Albumin & $23.602(0.799-696.807)$ & 0.067 \\
adjusted calcium & $2.559(0.225-29.113)$ & 0.449 \\
Phosphorus & $1.496(0.419-5.337)$ & 0.535 \\
Creatinine & $1.321(0.707-2.470)$ & 0.383 \\
Hemoglobin & $0.150(0.034-0.656)$ & 0.012 \\
Kt $/$ N & $3.983(0.155-102.457)$ & 0.404 \\
nPCR & $5.244 \mathrm{e}-7(1.59 \mathrm{e}-11-0.017)$ & 0.006 \\
$\% C G R$ & $1.011(0.950-1.076)$ & 0.737 \\
\hline
\end{tabular}

has been observed in the items of "symptoms and problems," "physical functioning," and "body pain". For these reasons, we concluded that the impact of complications on HADS would be insignificant.

The issues of this study are the small-sized examination at a single facility and cross-sectional study. A larger-scale study based on multicenter facilities and observations would be necessary in the future.

\section{Conclusions}

About 30\% of hemodialysis patients experienced "unstable psychological conditions." Patients with "unstable psychological conditions" overall had a low KD-QOL, especially related to items for "effects of kidney disease," "social support," and "general health perceptions." A possibility was suggested that the major causes were the restrictions of social activity by hospital visits and treatment and unique psychological conditions.

\section{Abbreviations}

QOL: Quality of life; HADS: Hospital Anxiety and Depression Scale; KDQOLSF: Kidney Disease Quality of Life Short Form; ADL: Activities of daily living; CES-D: Center for Epidemiological Studies Depression Scale; DOPPS: Dialysis Outcomes and Practice Patterns Study

\section{Acknowledgments}

We sincerely thank the patients who are undergoing maintenance hemodialysis and the dialysis center staff of Seitetu Memorial Hospital, Kamaishi-City, Iwate Prefecture, Japan.

\section{Authors' contributions}

JT designed the research and wrote the paper. TA, MK, NS, and YT performed the research. TM and JS analyzed the data. KF and KO provided methodological advice on study design. TK and WO kindly reviewed and revised the manuscript. All authors read and approved the final version of the manuscript.

\section{Funding}

This study was not supported by any grants or funding.

\section{Availability of data and materials}

The datasets analyzed during the present study are available from the corresponding author on reasonable request.

\section{Ethics approval and consent to participate}

This study was approved by the hospital's ethics committee of Seitetsu Memorial Hospital (approval number: 011) and was conducted under the Declaration of Helsinki. 


\section{Consent for publication}

All authors agreed on the publication of this study.

\section{Competing interests}

The authors declare that they have no competing interests.

\section{Author details}

'Department of Urology, School of Medicine, Iwate Medical University, 2-1-1, Idaidori, Yahaba-cho, Shiwa-gun, Iwate 028-3695, Japan. ²Dialysis Center, Iwate Medical University Hospital, 2-1-1, Idaidori, Yahaba-cho, Shiwa-gun, Iwate 028-3695, Japan. ${ }^{3}$ Dialysis Center, Seitetsu Memorial Hospital, 4-3-7, Osano-cho, Kamaishi-shi, Iwate 026-0052, Japan. ${ }^{4}$ Department of Neuropsychiatry, School of Medicine, Iwate Medical University, 2-1-1, Idaidori, Yahaba-cho, Shiwa-gun, Iwate 028-3695, Japan.

\section{Received: 9 June 2019 Accepted: 6 April 2020}

Published online: 22 April 2020

\section{References}

1. Masakane I, Taniguchi M, Nakai S, Tsuchida K, Goto S. Wada a, et al. Annual dialysis data report 2015, JSDT Renal Data Registry. Renal Replacement. Therapy. 2018:4:19.

2. Chilcot J, Wellsted D, Silva-Gane MD, Farrington K. Depression on dialysis. Nephron Clin Pract. 2008:108:c256-64

3. Kimmel PL, Peterson RA, Weihs KL, Simmens SJ, Alleyne S, Cruz I, et al. Multiple measurements of depression predict mortality in a longitudinal study of chronic hemodialysis outpatients. Kidney Int. 2000;57:2093-8.

4. Lopes AA, Bragg J, Young E, Goodkin D, Mapes D, Combe C, et al. Depression as a predictor of mortality and hospitalization among hemodialysis patients in the United States and Europe. Kidney Int. 2002;62: 199-207.

5. Fukuhara S, Green J, Albert J. MiharaH, Pisoni R, Yamazaki S, et al. Symptoms of depression, prescription of benzodiazepines, and the risk of death in hemodialysis patients in Japan. Kidney Int. 2006;70:1866-72.

6. Farrokhi F, Abedi N, Beyene J, Kurdyak P, Jassal SV. Association between depression and mortality in patients receiving long-term dialysis: a systematic review and meta-analysis. Am J Kidney Dis. 2014:63:623-35.

7. Zigmond AS, Snaith RP. The hospital anxiety and depression scale. Acta Psychiatr Scand. 1983;67:361-70.

8. Hays RD, Kallich JD, Mapes DL, Coons SJ, Amin N, Carter WB. Kidney disease quality of life short form (KDQOL-SFTM), version 1.3. A manual for use and scoring. Santa Monica. CA: RAND, P-7994, 1997.

9. Kugaya A, Akechi T, Okuyama T, Okamura H, Uchitomi Y. Screening for psychological distress in Japanese cancer patients. Jpn J Clin Oncol. 1998;28: 333-8.

10. Olssøn I, Mykletun A, Dahl AA. The Hospital Anxiety and Depression Rating Scale: a cross-sectional study of psychometrics and case finding abilities in general practice. BMC Psychiatry. 2005:14:46

11. Hays RD, Kallich JD, Mapes DL, Coons SJ, Carter WB. Development of the Kidney Disease Quality of Life (KDQOL ${ }^{\mathrm{TM}}$ ) instrument. Qual Life Res. 1994;3: 329-38.

12. Green J, Fukuhara S, Shinzato T, Miura Y, Wada S, Hays RD, et al. Translation, cultural adaptation, and initial reliability and multitrait testing of the Kidney Disease Quality of Life instrument for use in Japan. Qual Life Res. 2001;10: 93-100

13. Welch $J$, Austin JK. Factors associated with treatment-related stressors in hemodialysis patients. ANNA J. 1999;26:318-25.

14. Mok E, Tam B. Stressors and coping methods among chronic haemodialysis patients in Hong Kong. J Clin Nurs. 2001:10:503-11.

15. Snaith RP. The Hospital Anxiety And Depression Scale. Health and Quality of Life Outcomes. 2003:1:29.

16. Palmer S, Vecchio M, Craig JC, Tonelli M, Johnson DW, Nicolucci A, et al. Prevalence of depression in chronic kidney disease: systematic review and meta-analysis of observational studies. Kidney Int. 2013;84:179-91.

17. Fukuhara S, Green J, Albert J, Mihara H, Pisoni R, Yamazaki S, et al. Symptoms of depression, prescription of benzodiazepines, and the risk of death in hemodialysis patients in Japan. Kidney Int. 2006;70:1866-72.

18. Mapes DL, Lopes AA, Satayathum S, McCullouh KP, Goodkin DA, Locatelli F, et al. Health-related quality of life as a predictor of mortality and hospitalization: the Dialysis Outcomes and Practice Patterns Study (DOPPS). Kidney Int. 2003;64:339-49.
19. Umegaki $H$, Yanagawa $M$, Endo $H$. Association of lower hemoglobin level with depressive mood in elderly women at high risk of requiring care. Geriatr Gerontol Int. 2011;11:262-6.

20. Vulser H, Wiernik E, Hoertel N, Thomas F, Pannier B, Czernichow S, et al. Association between depression and anemia in otherwise healthy adults. Acta Psychiatr Scand. 2016;134:150-60.

21. Pu L, Zou Y, Wu S, Wang F, Zhang Y, Li G, et al. on behalf of the C-STRIDE study. Prevalence and associated factors of depressive symptoms among chronic kidney disease patients in China: results from the Chinese Cohort Study of Chronic Kidney Disease (C-STRIDE). Journal of Psychosomatic Research 2020; https://doi.org/10.1016/j.jpsychores.2019. 109869.

22. Oliveira CM, Costa SP, Costa LC, Pinheiro SM, Lacerda GA, Kubrusly M. Depression in dialysis patients and its association with nutritional markers and quality of life. J Nephrol. 2012;25:954-61.

23. Abdulan IM, Onofriescu M, Stefaniu R, Mastaleru A, Mocanu V, Alexa ID, et al. The predictive value of malnutrition for functional and cognitive status in elderly hemodialysis patients. Int Urol Nephrol. 2019:51:155-62.

24. Cukor D, Halen NV, Asher DR, Coplan JD, Weedon J, Wyka KE, et al. Psychosocial intervention improves depression, quality of life, and fluid adherence in hemodialysis. J Am Soc Nephrol. 2014;25:196-206.

\section{Publisher's Note}

Springer Nature remains neutral with regard to jurisdictional claims in published maps and institutional affiliations.
Ready to submit your research? Choose BMC and benefit from:

- fast, convenient online submission

- thorough peer review by experienced researchers in your field

- rapid publication on acceptance

- support for research data, including large and complex data types

- gold Open Access which fosters wider collaboration and increased citations

- maximum visibility for your research: over $100 \mathrm{M}$ website views per year

At $\mathrm{BMC}$, research is always in progress.

Learn more biomedcentral.com/submissions 